\title{
Young adult carers: making choices and managing relationships with a parent with a mental illness.
}

Dr Kate Blake-Holmes.

School of Social Work, University of East Anglia, Norwich, Norfolk, NR4 2JT, UK. Kate.BlakeHolmes@uea.ac.uk

\begin{abstract}
Objective

While there is a growing body of research focusing on young carers, less is known about young people caring for a parent with a mental illness and their experiences as they move into adult life.
\end{abstract}

\section{Method}

This paper reports the findings of a qualitative research project. Using thematic narrative analysis of interview data, insight is gained into the participants' experiences of their parents' mental illness and how they made sense of them.

\section{Results}

The term young carer implies that the role stops once the child reaches maturity, however, care for parents often continues into adulthood. Key challenges that young adult carers face include: education and employment; managing relationships; becoming a parent; exercising agency and maintaining boundaries.

\section{Discussion}

This study extends our knowledge of young carers' experiences and support needs during the transition to adulthood and suggests the need for services to support parents so that young adult carers are able to make choices about their own lives.

Keywords: Young adult carers, parental mental illness, transition, agency. 


\section{Background}

From the body of literature relating to children growing up with a parent with a mental illness, a clear picture of emotional and physical need is emerging (Power et al., 2016; Reupert \& Maybery, 2009; Rouf, 2014). It is important to note that neither parents with mental illness nor their children are a homogeneous group. Not all parents will have their ability to parent compromised, nor will all children be significantly affected or step in to a caring role (Boursnell, 2007).

However there are occasions when the parent/child relationship is affected by the severity or chronicity of the parent's mental illness. This can manifest itself in a range of areas of parenting, such as a lack of insight into the impact that their mental illness has upon the child, an inability to emotionally attune to the child, a lack of capacity to physically care for the child during acute episodes of illness and a paucity of social networks or support (Boursnell, 2007; Gatsou, et al., 2015).

Research suggests that many of the children growing up with a parent with mental illness provide care for their parent (Abraham \& Aldridge, 2010). This takes the form of both instrumental care, such as domestic duties, caring for younger siblings, medication management, and emotional care, such as attending to their parents' worries and distress, responding to crisis and keeping their parents safe.

While recognition of the needs of young carers is within the literature, less is known specifically about the needs of young carers caring for a parent with mental illness, where the care may be difficult to quantify. There are a significant number of children growing up with a parent with mental illness, who provide care but do not receive any recognition or support (Kallander et al., 2018).

Providing care for a parent is not in itself detrimental to a child; indeed it can be a positive experience, an expression of love and a thing to be proud of (Petrowski \& Stein, 2016). However it can become damaging if the level of care provided and the role and responsibilities attributed to the child fall far beyond what could reasonably be expected. If the roles in the family subsystem become skewed and the child takes on an adult role beyond their developmental years it can negatively impact their own needs, coping skills and resilience (Abraham \& Stein, 2013). McCormack, et al (2017) defined the 'caretaker 
child' as demonstrating intuitive behaviours designed to anticipate and meet the needs of others. Such behaviours are designed to keep themselves and their family safe, while maintaining an emotional link with their parent. Achieved by placing their own needs as secondary while developing a highly attuned ability to read and respond to unpredictable behaviour, the caretaker role can lead to a constant state of adaptive vigilance. While such behaviours may be thought of by health and social care services staff as a demonstration of resilience and competence, in reality it could be masking the needs of a child who is emotionally exhausted, scared and unable to reach for support (Gray, Robinson, \& Seddon, 2008). The risk of emotional exhaustion is a key feature in research with young carers, however the concept of young carer suggests those needs end once the child becomes an adult, whereas in reality the care they give often does not end in such a linear manner. As such, from a research perspective the needs of these young adult carers has been largely neglected (Abraham \& Stein, 2013; Boumans \& Dorant, 2018; Hamilton \& Adamson, 2013). In considering the needs of young adult carers it is important to reflect first on the distinct needs of young adults themselves. The developmental stage of early adulthood is of particular interest as it sets the scene for later life (Scales et al., 2016). It represents a time of life when young people reach for independence, autonomy and make significant life choices. Individual temperament, family composition and social environment shape the way young adults manage key stages in their life course, however inequalities such as class and gender also exert a powerful influence over their lives, transitions and agency (Furlong, 2009). Research focusing on young adults' transitions to adulthood has had a tendency to emphasize the structural influences on transitional changes in the young adults lives, often not recognising the active role they can take in shaping important dimensions of their transition into adulthood through their own reaction and response to the structural influences (Evans, 2002).

Such individual reactions and responses are conceptualised as agency, a process of social engagement within which an individual proactively resists external pressures, contextualises past assumptions and envisions a future self (Evans, 2002). This can be complicated for young adult carers whose choices and opportunities may be restricted (Boumans \& Dorant, 2018; Levine et al., 2005). Young adult carers inevitably exercise agency within a number of constraints. These constraints are formed from interconnected factors ranging from; family 
composition, obligations and expectations, alongside the intensity and duration of the parents' illness, to the policy and service availability which influences the care they provide, and societal factors such as gender, ethnicity and socioeconomic status (Hamilton \& Adamson, 2013). As such the bounded agency (Evans 2002) of young adult carers is not simply an expression of personal desire and resilience, but rather is a socially situated process.

A further key concept related to the agency of young adult carers is that of control, specifically their own construction of control beliefs, which are defined as the subjective representation of the individual's own capability to exercise control within their life (Evans, 2002). As a personal construct these control beliefs are influenced by environmental factors and can change and shift across the life course and in different domains of an individual's life. For young adult carers it is clear that such bounded agency, potentially constrained control beliefs and on-going care responsibilities can lead to difficulties in the transitions necessary in growing up.

When examining the passage into adulthood we must first clarify what is meant by terms such as transitions. Transitions to adulthood have been described by Scales (et al., 2016) as the engagement with specific opportunities, which provide a platform from which to implement aspirations and participate in adult life. Leaving familiar roles of childhood and adolescence and taking on new responsibilities, transitions can also function as turning points providing an opportunity for re-evaluation, change and identity formation. These transitions are linked to a complex interaction between individual agency, structural opportunity and social pathways. People do not just have their environment imposed upon them, but are able to interact and shape the environments that influence them, giving the hope that there could be multiple pathways towards a successful adulthood (Scales et al., 2016).

Becoming an adult requires the navigation of multiple transitions; the young person also needs to be able to construct a congruent biography, sense of identity and personal agency. While this is true for all young people, there is additional complexity for those who are also managing the specific issues raised by caring for a parent with a mental illness. This prompted the research question of how do adults who cared for a parent with a mental illness make sense of their experience and what impact does this have on them as adults? 


\section{Methods}

The focus of this paper is an exploration of the experiences of young adults who grew up with a parent with mental illness, with adults asked to recall their experiences and understanding of their parent's mental illness throughout their life course. This qualitative research involved biographical narrative interviews (Wengraf, 2001) with 20 individuals from across the United Kingdom who identified as having grown up with a parent with severe and enduring mental illness. While the study was not limited to specific illnesses or engagement with services, statutory eligibility criteria were applied and it appeared that all of the participants' parents would have met the threshold of severe and enduring mental illness as required for secondary mental health services. The classification of severe and enduring mental illness describes a diagnosed mental disorder which has a significant and persuasive impact on an individual's daily life. Careful consideration was given to the impact of the study and the interview process on particpants with ethical approval granted by the University Ethics Committee.

Recruitment was conducted through the researcher speaking at public events, such as Mind and Young Carers' conferences, and through social media. The sample represented a diverse group. Their ages ranged between 19 and 54 years old with a mean age of 31 . Four of the participants identified themselves as coming from a minority ethnic background. Four were siblings and six still lived with their parents. The gender imbalance in the participants (five male, fifteen female) was also reflected in the parent that they spoke about; five of the participants spoke about their fathers, twelve spoke about their mothers and three spoke about both their parents as being mentally ill, however they tended to focus predominately on their memories of their mother.

Participants were invited to tell their story from childhood to the present day. Consistent with the biographical narrative method (Wengraf, 2001) the interviewer listened with minimal interruption, questions or prompts. The interviews were audio recorded and lasted an average of 2.25 hours. Each interview was then transcribed verbatim.

The data were analysed using a thematic narrative method (Riessman, 2008), with regular opportunity to review the data analysis with an academic supervisory team. Transcripts were coded and an index was created for each participant. Emerging themes were visually 
mapped for each participant. These were not selected to be statistically representative but rather to develop theoretical exploration and argument. In order to retain a sense of the narrative, a biographical account was developed for each interview, isolating and ordering narrative episodes into a chronological timeline. In order to keep the narratives separate, each interview was analysed individually, engaging in an iterative process of expanding and collapsing thematic categories and narrative interpretation. Finally, coding and chronologies were combined to examine the manner in which themes and narratives interacted within and across the cases.

\section{Findings}

Analysing themes from participants' narratives of their childhood and transitions to adulthood. Five areas were identified as presenting particular challenges for young adult carers; education and employment, relationships with partners, becoming a parent, exercising agency and maintaining boundaries.

\section{Education and employment}

Participants spoke of the impact their caring responsibilities had upon their experiences of further education and employment. Many spoke of the impact that their caring responsibilities had upon their ability to engage with education, such as tiredness, distraction and worry about what was happening at home. Some felt that certain options were unavailable to them and they had few choices.

If I had the choice I would be at uni now, l'd be doing my teaching degree and my life would be completely different if I wasn't caring. (Holly) Whereas others spoke of the level of adjustment they had to make, which included only being able to take employment that offered hours which fitted in around their parent's care needs, such as Jenny working nightshifts to ensure she was home during the day. Accessing alternative support for their parents was often difficult, either through a lack of resources or because of their parent's specific needs or fear of allowing alternative carers into the home. At times the parent's need for care was contrary to their expressed desire to see their child happy and independent. When recalling her decision to leave university to care for her mother, Alicia reflected on the difficulty of managing the contradiction between what her mother says she wants for her and her demands for Alicia's caring role to continue. 
I don't think mum wants to hold me back, but I think she feels safer when I'm there and I think the thought of me moving on scares her. She's told me the thought of being alone scares her to death. She doesn't want to be alone but my mum's stubborn she won't have carers. (Alicia)

The majority of participants spoke of the practical difficulties they faced in balancing their caring responsibilities with their educational or employment commitments. However for some this was further exacerbated by the emotional tension and sense of duty they held towards their parents.

\section{Relationships with partners}

Several of the participants spoke about the difficulties they had forming and maintaining relationships with partners. None of the five participants who still lived with their parents were in a relationship and all spoke about the impossibility of having the time to form relationships, as they would wish, alongside their caring responsibilities and the intensity of the relationship they had with their parent.

I've always wanted to be married and have kids by the time I was $21 . . . I$ m 21 now I haven't been in a relationship for 5 years. I don't have the time to go out and meet people ... I don't think I'm going to have kids until I'm about 30 at this rate. (Alicia)

Others, like Jess, Terry and Natalie spoke about partners not understanding their caring role, forcing them to feel pulled between them and their parents. Emily, Jess, Lucy and Monica also expressed an anxiety which prevented them from entering into long term relationships as they feared they were not emotionally equipped or that there was a risk they may become unwell and replicate the difficulties they had witnessed from their parents throughout their childhood. This fear was so great for Emily that she had a document that she had asked her fiancé to sign with her. Referring to it as a 'pre-nup' it gave her partner instructions and permission to leave her and take full custody of any children they might have should she show symptoms of mental illness similar to her mother's. 
I said to [him] when we got engaged, I think we should write a pre-nup in case I go mad and I'm horrible to you like my mum was. (Emily)

As with education and employment, the logistics of a relationship were hard to manage. However there was also a sense of fear regarding their ability to make a healthy connection with a partner on an emotional level and the potential for them to repeat the relationship behaviours they had seen as children.

\section{Becoming a parent}

Monica, Emily, Roman and Lucy spoke about making an active decision not to have children based upon their childhood experiences of parental mental illness, either through feeling emotionally ill equipped to parent or for fear of emulating their own parent. Jess felt that she would need to 'work' on herself before she could consider opening the possibility of becoming a parent.

I want to have kids and I want to have a happy healthy family, and I know at the moment there's a lot in my life that hasn't been healthy and I need to be able to get to the point where I know what's a healthy environment and I can create a healthy environment. (Jess)

Sophia planned to have children in the future but already anticipated the difficulty she might have in balancing her children's needs with those of her mother. She also predicted that she would not be able to rely on her mother as a supportive grandmother the way her friends might be able to rely on their mothers. This concern was evident in Vivienne's current situation as she grappled with the dilemma of whether she would leave her young baby to attend to her mother during one of her regular relapses. Vivienne explained that for the past 10 years (since the age of 14) Vivienne had spent 4-6 weeks with her mother every two years, supporting her through her relapse, risk managing her suicidal, self-harming and aggressive behaviour and re-establishing her medication regime. However, this time she also had to consider the risk to her own baby and the difficult choices facing her.

I've always felt like I was kind of having to look after them and, now I've got a child of my own I just don't want to do that anymore. I really just want to sort of focus on [my baby] and our life together, and my partner's not 
particularly impressed with it all either. Last time my mum was ill, I was like I need to go out there and he was just like, just don't... I feel guilt all the time with my mum, and I don't know why because I've got no reason to be beholden to her, and I don't owe her anything. But she's just got a way of like manipulating me. So it's all very well me saying, I'm not going to go over there anymore if she's ill again. But I don't know if when it came down to it I would actually not. I certainly wouldn't bring [my baby] with me, she'd be, you know I'd have her stay here with her dad, but, I don't know, it's difficult to say. (Vivienne)

Seb, Georgina, Vivienne and Robin spoke about feeling the need to actively manage the relationship their children might have with their grandparents. For Robin this resulted in making the decision not to allow any kind of relationship to form, severing all contact with her father once her first child was born, whereas Seb, Vivienne and Georgina negotiated agreements that their parent's contact with their child would be limited and supervised. However, Georgina expressed concern as to how long she would be able to tightly control the relationship between her son and her mother.

I'd never leave him with her. No way, not because I don't think she could cope with him, but because of any potential emotional damage she could do to him. I'm sure she would be very good with him because she is very good with babies but I want to watch her all the time... I do worry about like when he wants to have a relationship with mum, one that I can't control, you know that there'll be times when she could, she'll talk to him and he'll be able to actually respond and I, I just, I do worry about that. (Georgina)

Within these diverse forms of negotiation and reflection, participants spoke about a shift in their perceptions regarding the caring relationship they had with their parents and the wish to make the right choices for themselves and their children. In terms of the practical and emotional challenge in becoming a parent themselves, participants faced a high level of complexity.

\section{Exercising Agency.}


A key part of the impact that their parent's mental illness had upon their transition into adulthood was the influence it had upon their sense of agency and ability to engage with the world around them. Sophia felt that the need to respond to her mother's mental illness presented a barrier to her pursuing her own aspirations.

She ruins everything like I always have to stop things or do things later do you know what I mean? It's like whenever I'm busy or have got lots of work to do she'll go into crisis and I'm so fed up of using her as an excuse (Sophia) Not only did Sophia feel that her mother's needs constricted her agency, they also negatively affected her sense of self and how she was viewed by others.

I want to break free from that now. I just want to be me. I really don't want to have to walk with this baggage. I don't want to be that person who's always got to go off to sort out her mum. I want to be like everyone else I don't want to come across as like a liability. (Sophia)

Whereas Terry's internalised representation of himself as a caregiver child meant that he felt that he psychologically held himself back in anticipation of a crisis that might come.

All I ever wanted was to be just settled, settled ordinary life... No chaos, or as little chaos as possible... I'm not really ambitious, I think I could have been but not with, I think going through that, all that turmoil, that does something to you. Cos you're always waiting for something to go wrong, you just can't dedicate yourself to something else $100 \%$. (Terry)

Sophia went on to discuss how she felt that the 'baggage' she currently carries in regards to her mother's mental illness will be enduring and subsequently will be something that she has no choice but to assimilate into her adult life and identity.

She's never going to get better, and I think that more than likely she's going to get worse because people get worse as they get older and she is always going to be a burden and she's not going to go anywhere. I'm always going to feel responsible, and as much as I say I'm having a break, I'm never going to actually have a break mentally... so it's like having a child you never gave birth to. (Sophia) 
This sense of relentless responsibility was also true for Georgina, Seb, Alicia, Holly and Vivienne. Like Sophia they strove to envisage how they would manage to balance the needs of their own adult lives with the demands of their parent's mental illness. However, for three of the young adult carers still living with their parents there seemed to be an overwhelming focus on the parent, which allowed little space for personal agency. For Jenny this left her feeling distressed and helpless.

I do get angry inside but I can't do anything about it. It's not going to solve anything ....So this is my life and I can't change it, I can't do anything about it. (Jenny)

While it is generally accepted that family experiences shape identities, the participants spoke about a high correlation between their parents' mental illness and their own ability to exercise agency and define their identity. This was most stark in the interviews of the young adult carers who expressed a feeling of hopelessness and a belief that their identity and opportunity would be inextricably interwoven with their parents' ongoing mental health needs.

\section{Creating and maintaining boundaries}

Throughout their interviews participants spoke of diverse strategies they took to make sense of their parents' illness and to manage the impact it had upon their own lives. These pathways were often represented as a continuum of both psychological and physical boundaries. For several of the participants they were able to create a protective psychological boundary for themselves by learning more about their parents' ill health and reconceptualising their own role within it. Natalie and Jess achieved this through professional support, whereas Seb, Georgina, Lucy and Freya spoke of choosing a career in mental health care. They described this as not only a natural progression of the skills they had developed through childhood but also an opportunity for them to psychologically reposition themselves with their parent.

My training was like a light bulb moment... I care about the people I work with if they're suicidal, but they're not my mum... it helps me make sense of my experience I suppose. (Lucy) 
This shift in the way they understood their parent's illness also allowed some participants to re-consider priorities and feel more in control.

Some of the things that she would have done before that would have got a real rise out of me, it would have controlled my behaviour. Now it would be like don't play that game with me. I'm not I'm not interested in engaging with it, that's your choice. I want to have a healthy life and I've given you a lot of my years. (Jess)

This was a particular theme for participants who became parents themselves and attempted to position their primary sense of responsibility to their partners and children above their parent. There was a suggestion in several of the narratives that this psychological shift was only possible in response to the needs of others as opposed to their own.

I think having a baby has helped to disconnect me from her. From the point that you're pregnant you're responsible for them and I knew that I couldn't allow myself to get too stressed by the situation because it wouldn't just impact me, it would impact my child. (Freya)

Equally, this shift could coincide with a physical distance being created. Lucy described how "happiness is a family 200 miles away" whereas Vivienne reflected on the on-going effort required to maintain a sense of psychological space for herself despite her mother living in another country.

I find our relationship really difficult to manage, mine and my mum's, I find it really difficult to set boundaries and maintain boundaries with her and I feel like it's always two steps forward and one step back. (Vivienne)

This need for a sense of understanding and boundaries was crucial for all of the participants within the study in a range of ways. The difference between positioning themselves as enmeshed and defined by their parents' mental illness or as self-determining and resilient, was less about the severity of their parents' illness and more about their own sense of physical and psychological independence. Ideally they were able to protect this independence through the maintenance of boundaries enabling them to adapt flexibly to the stresses in both their own lives and those of their parents, being close and supportive in times of needs while still being able to maintain a space for themselves. 


\section{Discussion and implications}

For all of the participants the complexities of their relationship with their parent and a sense of responsibility to provide care continued into their adult lives. As other research suggests the impact of this upon their transition into early adulthood was influenced by the people and resources available to them (Boumans \& Dorant, 2018; Evans, 2002). For example, both the practical and emotional challenges that young adult carers face impact and influence the way that they are able to engage with educational and early employment opportunities. This also makes it difficult for them to establish significant relationships of their own outside of the family system, mirroring messages from research regarding the difficulties that young carers face (Abraham \& Aldridge, 2010). However, as young carers reach the age of 18 the acknowledgement and support for these needs fall away in many areas.

While the concept of emerging adulthood as being a developmentally significant period of life is widely recognised (Furlong, 2009), this study would suggest that this may be more complex for young adult carers and they may have 'grown up fast' in certain areas while their emotional and psychological growth could have been delayed in others (McCormack et al, 2017). Furthermore, their need for support can also reach into their adult life, for example as they attempt to negotiate their own transition to becoming a parent with their ongoing relationship with their own parent. It is clear that their sense of agency, capacity to negotiate relationships and create boundaries were equally significant for their sense of self-determinism and hope for the future.

Furthering the concept of bounded agency as the "boundaries or barriers that circumscribe and sometimes prevent the expression of agency" (Evans, 2002 p262), the extent to which the participants saw themselves as either enmeshed or self-determining was integral to their own sense of agency and resilience. Plotted across a spectrum it can be seen that the participants who felt that they were most able to manage their parent's ill health, were those who held that their relationship with their parent could be fluid. They were able to draw close to their parent at times of need without fearing that they would become enmeshed and unable to move back to a point where they could focus on their own emotional needs, external commitments and aspirations. Whereas those who described themselves as fixed in the role of either rejecting or rescuing appeared most consumed by 
their parents' mental illness and unable to manage the relationships necessary for successful transitions into adulthood. The fluidity that some participants were able to develop within the confines of their bounded agency suggested a level of resilience. This gave them a particular mindset which enabled them to adapt flexibility not only within their relationship with their parent but also when faced with other stresses in their adult life.

Furthermore, while all of the participants in the study spoke of negative aspects which they felt were defining factors within their experiences of growing up with a parent with a mental illness, several also spoke of gaining specific skills and strengths as a result of their difficulties. Jess spoke of feeling that her childhood had enabled her to develop a "swiss army knife" of extraordinary skills and abilities that she could use to help others within her career. Again these individuals were not only able to draw strength from their adversity but also demonstrated an ability to step out of their own sense of bounded agency, describing a more fluid, balanced approach which allowed them to set limits to their personal sense of responsibility for their parents whilst also seeing themselves and their own families as entitled to some freedom and fulfilment in life.

The examples of the acquisition of skills and a resilient mind-set illustrated in this study could supported in childhood and adolescence by promoting emotional regulation, agency and self-esteem within child. Furthermore, there is a clear need to support young adults and their parents with mental illness during the transitional stages into adulthood to offer advice, guidance and support in exercising their agency and developing appropriate boundaries.

However, for policies and intervention to be effective they must be cognisant of the interplay between structural influences on young adult carers and their own sense of agency and control. Services need to be flexible, combining both practical support, such as the provision of additional support to the parent as they manage the transition of their child (and carer) leaving home, and emotional support for the young person and their parent to renegotiate boundaries within their relationship.

Limitations

A bias emerged in the recruitment which had not been anticipated. While the recruitment literature was careful not to direct potential participants towards a particular diagnosis or 
experience, it emerged that all of the participants came to the study with memories of childhood adversity and trauma. These negative experiences cannot be generalised across the population, nor is it claimed that all children growing up with a parent with a mental illness experience such challenges. However the disproportionate representation of individuals motivated to share their stories of sadness and trauma is reflective of both the paucity of opportunities to have their voices heard, and the ongoing impact that these childhood experiences still have upon them as adults

\section{References}

Abraham, K., \& Aldridge, J. (2010). Who cares about me? Manchester: Manchester Carers Forum.

Abraham, K., \& Stein, C. (2013). When mom has a mental illness: Role reversal and psychosocial adjustment among emerging adults. Journal of Clinical Psychology, 69(6), 600-615.

Boumans, N. P. G., \& Dorant, E. (2018). A cross-sectional study on experiences of young adult carers compared to young adult noncarers: Parentification, coping and resilience. Scandinavian Journal of Caring Sciences.

Boursnell, M. (2007). The silent parent: Developing knowledge about the experiences of parents with mental illness. Child Care in Practice, 13(3), 251-260.

Evans, K. (2002). Taking control of their lives? Agency in young adult transitions in England and the New Germany. Journal of Youth Studies, 5(3), 245-269.

Furlong, A. (2009). Reconceptualizing youth and young adulthood. In A. Furlong (Ed.), Handbook of Youth and Young Adulthood: New Perspectives and Agendas (pp. 1-13). London: Routledge.

Gatsou, L., Yates, S., Goodrich, N., \& Pearson, D. (2015). The challenges presented by parental mental illness and the potential of a whole-family intervention to improve outcomes for families. Child \& Family Social Work, 388-397. 
Gray, B., Robinson, C., \& Seddon, D. (2008). Invisible children: Young carers of parents with mental health problems - The perspectives of professionals. Child and Adolescent Mental Health, 13(4), 169-172.

Hamilton, M. G., \& Adamson, E. (2013). Bounded agency in young carers' lifecourse-stage domains and transitions. Journal of Youth Studies, 16(1), 101-117.

Kallander, E. K., Weimand, B. M., Becker, S., Van Roy, B., Hanssen-Bauer, K., Stavnes, K., ... Ruud, T. (2018). Children with ill parents: extent and nature of caring activities. Scandinavian Journal of Caring Sciences, (12), 16-19.

Levine, C., Hunt, G. G., Halper, D., Hart, A. Y., Lautz, J., \& Gould, D. A. (2005). Young adult caregivers: A first look at an unstudied population. American Journal of Public Health, 95(11), 2071-2075.

McCormack, L., White, S., \& Cuenca, J. (2017). A fractured journey of growth: making meaning of a 'Broken' childhood and parental mental ill-health. Community, Work \& Family, 20(3), 327-345.

Petrowski, C. E., \& Stein, C. H. (2016). Young womens accounts of caregiving, family relationships, and personal growth when mother has mental illness. Journal of Child and Family Studies, 25(9), 2873-2884.

Power, J., Goodyear, M., Maybery, D., Reupert, A., O’Hanlon, B., Cuff, R., \& Perlesz, A. (2016). Family resilience in families where a parent has a mental illness. Journal of Social Work, 16(1), 66-82.

Reupert, A., \& Maybery, D. (2009). Guest Editorial: Practice, policy and research: Families where a parent has a mental illness. Advances in Mental Health, 8(3), 210-214.

Riessman, C. (2008). Narrative methods for the human sciences. London: Sage.

Rouf, K. (2014). We need to talk : Parental mental health problems and their potential impact. Educational and Child Psychology, 31(3), 71-84.

Scales, P. C., Benson, P. L., Oesterle, S., Hill, K. G., Hawkins, J. D., \& Pashak, T. J. (2016). The 
dimensions of successful young adult development: A conceptual and measurement framework. Applied Developmental Science, 20(3), 1-25.

Wengraf, T. (2001). Qualitative research interviewing: biographical narrative and semi structured methods. London: Sage. 